\title{
Cardiopulmonary fitness test among Nepalese students
}

\author{
Hada S, Amatya S, Gautam K \\ Department of Clinical Physiology, Kathmandu Medical College, Sinamangal, Kathmandu, Nepal
}

\begin{abstract}
Background and Objectives: Maximum Oxygen uptake $\left(\mathrm{VO}_{2}\right.$ max) is a good predictor of cardiopulmonary and muscle fitness. Maximum oxygen uptake is defined as the highest rate at which oxygen can be taken up and utilize by body during severe exercise. The present study aims to find out the level of $\mathrm{VO}_{2}$ max using Mc Ardle equation and to compare obtained values from Chatterjee's equation in Nepalese population.

Methodology: Maximum oxygen uptake was determined by using the Queen's college step-stool of 16.25 inches and popular Mc Ardle equation. Stepping was done for a total duration of 3 minutes at the rate of 24 cycles per minute for males and 22 cycles per minute for females. After completion of the exercise, subjects remained standing while the carotid pulse rate was taken as heart rate. Maximum oxygen uptake was calculated using obtained heart rate.

Results: Queen's college step test (QCT) was used as a submaximal exercise and the estimated $\mathrm{VO}_{2}$ max in boys and girls was $48.8 \pm 7.3 \mathrm{ml} / \mathrm{kg} / \mathrm{min}$ and $37.4 \pm 2.7 \mathrm{ml} / \mathrm{kg} / \mathrm{min}$ respectively with Mc Ardle equation and the value was higher when compared with Chatterjee's equations. The value of $\mathrm{VO}_{2}$ max was observed and found to be less in smokers and sedentary individuals.

Conclusion: As the values of $\mathrm{VO}_{2}$ max obtained from different equations are different, this research strongly argues the need of developing a prediction equation specifically for the Nepalese population.

Keywords: Cardiopulmonary fitness, Submaximal exercise, V02max
\end{abstract}

\section{INTRODUCTION}

Nepal Health Research Council (NHRC) estimated that $38 \%$ of the adult population in Nepal suffers from cardiovascular diseases with about half suffering from hypertension [1]. The prevalence is highest in the Central development region where people have a more sedentary lifestyle [2]. Studies have shown thatthere is a strong relation between cardiopulmonary fitness and mortality due to cardiovascular diseases including hypertension, myocardial infarction and also the complications 
of diabetes [3]. Cardiovascular fitness is also of interest in relation to rehabilitation of cardiac problems, improved performance in neuropsychological test, increasing fitness concern of people.

As the values of $\mathrm{VO}_{2}$ max varies among different populations, the present study aims to estimate the level of $\mathrm{VO}_{2}$ max in young healthy Nepalese adults using a well-established submaximal exercise test, the Queen's College Step test. Since different prediction equation have been proposed, the outcome with these equations will be compared.

\section{MATERIAL AND METHODS}

The study was conducted in the Department of Physiology, Kathmandu Medical College, Duwakot. One hundred and sixty medical students of MBBS I and II year volunteered for the test. Study was approved by Ethics committee of Kathmandu Medical College and written consent was taken from volunteers. The protocol was fully explained and written consent was taken from the volunteers. Individuals with cardiac and lung diseases, those having problems in the lower limbs or using drugs known to influence the cardiovascular system were excluded from the study. The subjects were asked to refrain from physical activity on the day of the test. All experiments were done in room temperature with participants dressed in suitable clothes. Anthropometric parameters like height and weight was measured using stadiometer with barefoot and in light clothes. BMI was categorized according to classification for Asian population [4].

To determine $\mathrm{VO}_{2}$ max, the Queen's college stepstool of 16.25 inches was used. Stepping was done for a total duration of 3 minutes at the rate of 24 cycles per minute for males and 22 cycles per minute for females.
A metronome was used to pace the stepping cycle in four step cadences; up-up, down-down continuously for 3 minutes. After completion of the exercise, subjects remained standing while the carotid pulse rate was monitored for 15 seconds from the $6^{\text {th }}$ second of the recovery period. The carotid pulse rate was taken as heart rate.

$\mathrm{VO}_{2}$ max was calculated from the measured heart rate, using the internationally accepted Mc Ardle equations:

\section{For Males:}

$\mathrm{VO}_{2} \max (\mathrm{ml} / \mathrm{kg} / \mathrm{min})=111.33-(0.42 \mathrm{x}$ pulse rate in beats per $\min$ ) [5]

\section{For Females:}

$\mathrm{VO}_{2} \max (\mathrm{ml} / \mathrm{kg} / \mathrm{min})=65.81-(0.1847 \mathrm{x}$ pulse rate in beats per min) [5]

For comparison, the following equations for the $\mathrm{VO}_{2}$ max determined for Indian adults were used (Chatterjee et al.).

\section{For Males:}

$\mathrm{VO}_{2} \max (\mathrm{ml} / \mathrm{kg} / \mathrm{min})=55.23-(0.09 \mathrm{x}$ pulse rate in beats/min) [6]

\section{For Females:}

$\mathrm{VO}_{2} \max (\mathrm{ml} / \mathrm{kg} / \mathrm{min})=54.12-(0.13 \mathrm{x}$ pulse rate in beats/min) [7]

For classification of aerobic fitness Katch et al. [5] categories were used as shown in Table 1. Statistical analysis was done using Microsoft Excel 2003. Values are given as Mean \pm Standard Deviation (SD). Student's t- test was used to compare results, taking $\mathrm{P}<0.05$ as significant. 


Table 1: Aerobic fitness classification according to Katch et al. [5]
\begin{tabular}{|c|c|c|c|c|}
\hline \multirow{2}{*}{ Category } & \multicolumn{2}{|c|}{ Male } & \multicolumn{2}{c|}{ Female } \\
\cline { 2 - 5 } & $\mathbf{1 3 - 1 9}$ years & $\mathbf{2 0 - 2 9}$ years & $\mathbf{1 3 - 1 9}$ years & $\mathbf{2 0 - 2 9}$ years \\
\hline Poor & $<35-38.3$ & $<33.0-36.4$ & $<25.0-30.9$ & $<23.6-28.9$ \\
\hline Fair & $38.4-45.1$ & $36.5-42.4$ & $31.0-34.9$ & $29.0-32.9$ \\
\hline Good & $45.2-50.9$ & $42.5-46.4$ & $35.0-38.9$ & $33.0-36.9$ \\
\hline Excellent & $51.0-55.9$ & $46.5-52.4$ & $39.0-41.9$ & $37.0-41.0$ \\
\hline Superior & $>55.9$ & $>52.4$ & $>41.9$ & $>41.0$ \\
\hline
\end{tabular}

\section{RESULTS}

A total of 158 healthy Medical students participated in the study, 79 females and 79 males. Anthropometric and cardiovascular variables for the study groups are summarized in table 2. Most participants were in the age group 18 to 21 with males slightly older than females. As shown in table 2, they were also taller and heavier as expected. Significant difference is seen for anthropometric parameters and blood pressure variables with lower values found for females. No difference was found for heart rate.

\begin{tabular}{|c|c|c|c|}
\hline Nariables & $\begin{array}{c}\text { Males } \\
\text { Mean } \pm \text { SD }\end{array}$ & $\begin{array}{c}\text { Females } \\
\text { Mean } \pm S D\end{array}$ & P value \\
\hline Age (yrs) & $20.00 \pm 1.00$ & $19.00 \pm 1$ & $0.002^{*}$ \\
\hline Height (m) & $1.69 \pm 0.06$ & $1.56 \pm 0.05$ & $0.000^{*}$ \\
\hline Weight (Kgs) & $63.50 \pm 10.40$ & $52.30 \pm 6.90$ & $0.000^{*}$ \\
\hline BMI & $22.20 \pm 3.20$ & $21.50 \pm 2.60$ & $0.028^{*}$ \\
\hline Systolic (mmHg) & $121.00 \pm 10.00$ & $111.00 \pm 9.00$ & $0.000^{*}$ \\
\hline Diastolic (mmHg) & $72.00 \pm 9.00$ & $67.00 \pm 9.00$ & 0.017 * \\
\hline Resting Heart rate & $77.00 \pm 8.00$ & $77.00 \pm 9.00$ & $0.50^{\mathrm{ns}}$ \\
\hline
\end{tabular}

The BMI was significantly higher in males than in females. Since the number of obese participants was very few, they were included in overweight category for the analysis.

Table 3: Estimated $\mathrm{VO}_{2}$ max according to different prediction equations in male and female

\begin{tabular}{|c|c|c|}
\hline $\mathrm{VO}_{2}$ max & $\begin{array}{c}\text { Male } \\
(\mathrm{ml} / \mathrm{kg} / \mathrm{min})\end{array}$ & $\begin{array}{c}\text { Female } \\
(\mathrm{ml} / \mathrm{kg} / \mathrm{min})\end{array}$ \\
\hline Mc Ardle equation & $48.80 \pm 7.30$ & $37.40 \pm 2.70$ \\
\hline Chatterjee's equation & $41.90 \pm 1.57$ & $34.00 \pm 1.90$ \\
\hline
\end{tabular}

Estimated $\mathrm{VO}_{2}$ max using Mc Ardle equation was significantly higher in males $(48.8 \pm 7.3)$ than in females (37.4 $\pm 2.7 ; \mathrm{P}<0.001)$ (Table: 3 ). The $\mathrm{VO}_{2}$ max obtained from Chatterjee's equation was significantly lower both for males (41.9 \pm 1.57 $\mathrm{ml} / \mathrm{kg} / \mathrm{min})$ and female $(34 \pm 1.9 \mathrm{ml} / \mathrm{kg} / \mathrm{min})$ compared to the Mc Ardle estimates. However the values for males and females were still significantly different $(\mathrm{P}<0.001)$ using Chatterjee's equations.

Figure1: Comparison of $\mathrm{VO}_{2}$ max obtained from Mc Ardle equation with Chatterjee's equation in males

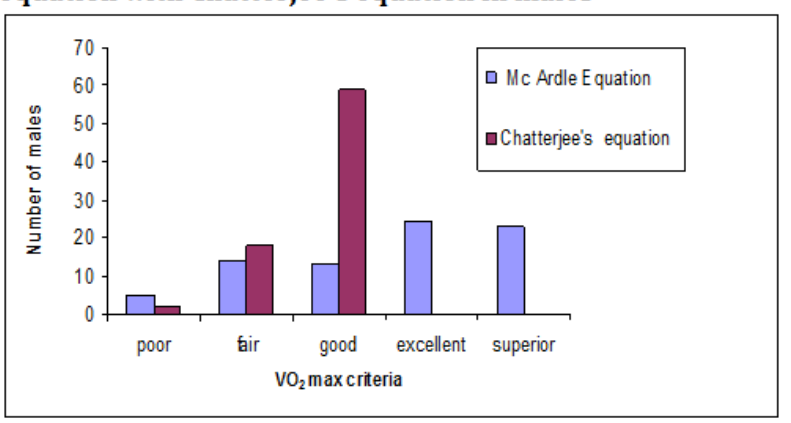

Fig 2 and 3 shows the comparison of $\mathrm{VO}_{2} \max$ obtained from Mc Ardle equation with Chatterjee's equation in males and females. For comparison, $\mathrm{VO}_{2}$ max was classified into different categories as shown in table 1 .Much lower values were observed in using Chatterjee's equation.

Figure 2: Comparison of $\mathrm{VO}_{2}$ max obtained from MC Ardle equation with Chatterjee's equation in females.

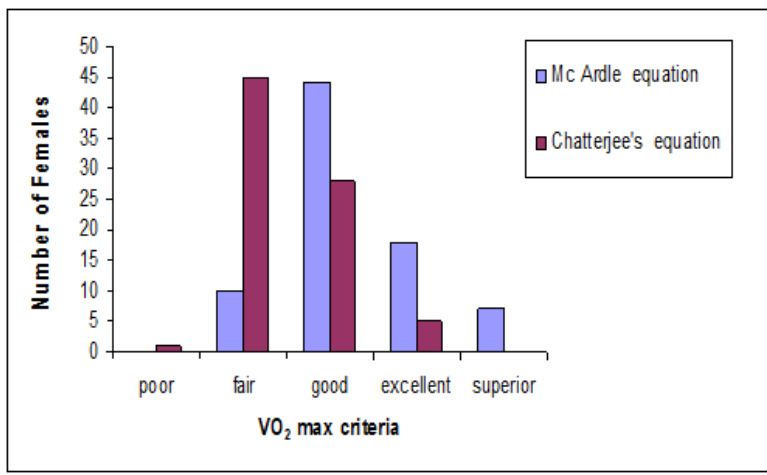


Of studied males, 16/69 reported that they were cigarette smokers. A significant difference was observed in $\mathrm{VO}_{2}$ max of these compared to non smoking males $(\mathrm{P}<0.01$; Table 4$)$. None of the studied females were smokers. The participants who played games (football, cricket), perform yoga, danced and were jogging were considered to be physically active. For both males and females this group differed significantly in $\mathrm{VO}_{2}$ max from their more sedentary counterparts (Tables5 and 6). There were also significant differences in $\mathrm{VO}_{2}$ max between overweight/obese and normal weight groups, both for males and females.

Table 4: Comparative study of $\mathrm{VO}_{2}$ max between smokers and non smokers according to Mc Ardle equations

\begin{tabular}{|c|c|c|c|}
\hline Variables & $\begin{array}{c}\text { No of } \\
\text { participants }\end{array}$ & $\begin{array}{c}\text { Vo } \text { max }_{\text {man }} \\
\text { (Mean } \pm \text { SD) }\end{array}$ & P value \\
\hline Smokers & 16 & $45.10 \pm 7.48$ & \\
\cline { 1 - 3 } Non smokers & & & \\
& 63 & $49.90 \pm 6.99$ & 0.009 \\
\hline
\end{tabular}

Table 6: Comparative study of $\mathrm{VO}_{2}$ max with different behavioural parameters in females according to Mc Ardle equations

\begin{tabular}{|c|c|c|c|}
\hline Variables & $\begin{array}{l}\text { No of } \\
\text { participants }\end{array}$ & $\begin{array}{l}\mathrm{VO}_{2} \max \\
(\text { Mean } \pm \\
\text { SD) }\end{array}$ & Pvalue \\
\hline Physically active & 13 & $39.10 \pm 3.07$ & \\
\hline Physically inactive & 66 & $36.90 \pm 2.50$ & 0.004 \\
\hline Normal & 59 & $37.70 \pm 2.70$ & \\
\hline Overweight/Obese & 17 & $35.90 \pm 2.49$ & 0.008 \\
\hline
\end{tabular}

Table 6: Comparative study of $\mathrm{VO}_{2}$ max with different behavioural parameters in females according to Mc Ardle equations

\begin{tabular}{|c|c|c|c|}
\hline Variables & \begin{tabular}{|l|} 
No of \\
participants
\end{tabular} & $\begin{array}{l}\mathrm{VO}_{2} \max \\
(\text { Mean } \pm \\
\text { SD) }\end{array}$ & Pvalue \\
\hline Physically active & 13 & $39.10 \pm 3.07$ & \\
\hline Physically inactive & 66 & $36.90 \pm 2.50$ & 0.004 \\
\hline Normal & 59 & $37.70 \pm 2.70$ & \\
\hline Overweight/Obese & 17 & $35.90 \pm 2.49$ & 0.008 \\
\hline
\end{tabular}

\section{DISCUSSION}

Physical fitness is not only required in sports but also to sustain ordinary life. Males had higher values of estimated $\mathrm{VO}_{2}$ max than their female counterparts as has been observed previously in studies from this country and abroad [6-8]. This difference is attributed to body composition. Untrained young female possess $25 \%$ of body fat whereas the corresponding value for men averages $15 \%$. Due to higher level of testosterone men also shows $10-14 \%$ increases in haemoglobin. Therefore the resulting increase in blood oxygen carrying capacity increases $\mathrm{VO}_{2}$ max in male [5, 9].

The values of $\mathrm{VO}_{2}$ max obtained in the study were higher than the values obtained for other South Asian populations in the same age group suggesting a higher aerobic capacity in Nepalese adult [9-11] .Such result could be predicted because of life style and geographical differences (Kathmandu: 1400 meters, Kolkata: 1.5-9 meters).

Estimated $\mathrm{VO}_{2}$ max of smokers was less than that of non smokers which is similar to the result obtained in other studies [11, 12]. However, the difference was smaller here, presumably because the volunteers recruited were recent, moderate smokers.

While comparing $\mathrm{VO}_{2}$ max of volunteers who are involved in some kind of physical activity like sports, dance, yoga etc with those who never exercise, the value is higher in those who involve in any kinds of physical activities. Variations in $\mathrm{VO}_{2}$ max during different mode of exercise reflect quantity of activated muscle mass.Aerobic exercise can only produce cardiovascular conditioning. Aerobic capacity with training improves between 6-20\% although it has been reported above 50\% [5]. A study conducted by Gromley et al. (2008) on 
effect of intensity of aerobic training on $\mathrm{VO}_{2}$ max found that improvement of $\mathrm{VO}_{2}$ max was

significant in those young adults who exercise in higher intensity [13].

The largest $\mathrm{VO}_{2}$ max improves occurs among sedentary individuals.

The values of $\mathrm{VO}_{2}$ max estimated from Mc Ardle equations were much greater than that from Chatterjee's equations. There were appreciable numbers of males in the "excellent" and "superior" categories with Mc Ardle equations whereas with Chatterjee's equations, they are limited to the "good" category. Similarly in females, there are only a few in the "excellent" and none in the "superior" category using Chatterjee's equation (Fig 1 and 2). According to our result it can be speculated that Mc Ardle equations overestimated $\mathrm{VO}_{2}$ max while Chatterjee's equation underestimated $\mathrm{VO}_{2}$ max, 2 . especially in males. Whatsoever is the reason is, this discrepancy points to there is a strong need 3 . to find a prediction equation for the Nepalese population, as there are difference in health, ethnicity and socioeconomic background 4 . compared to Indians as well as to western populations.

\section{CONCLUSION}

This study shows that there are significant differences in $\mathrm{VO}_{2}$ max between the genders and between adults with different behavioural habits. The result obtained from Chatterjee's equations does not seem to be realistic in our 7 . group of population as Nepal is a hilly region and walking in such landscape is different from walking in plain land as in India. Also in this 8. study group, no males were categorized as excellent even though male are more athletic study group, no males were categorized as excellent even though male are more athletic than females. It seems that the value of $\mathrm{VO}_{2} \max$ in Nepalese population is overestimated by Mc Ardle equations and underestimated by Chatterjee's prediction equations.

The discrepancy of $\mathrm{VO}_{2}$ max among different population underlines the need to derive a prediction equation specific for our population.

\section{ACKNOWLEDGEMENT}

Authors wish to thank Prof. Sivert Lindstrom for his help and MBBS 14 and 15 batch students who volunteered for the study.

\section{REFERENCE}

1. Nepal Health Sector Programme Implementation plan II (2010-2015). Final draft. Ministry of health and population; 2010.

Prevalence of Non communicable disease in Nepal. Nepal Health Research Council. Ramshahpath; 2010

Mercedes R, Samuel S, Nehgme R et al. Cardiorespiratory fitness in young adulthood and the development of cardiovascular disease risk factors. JAMA 2003; 290(23):3092-3100.

Nishida C: Appropriate body mass index for Asian populations and its implications for policy and intervention strategies. The Lancet 2004; (363), 157-163.

5. Katch VL, Mc Ardle W D, Katch F I. Essentials of Exercise Physiology. Philadelphia: Lippincott Williams and Wilkins: 2011

6. Chatterjee $\mathrm{S}$, Chatterjee $\mathrm{P}$, Mukherjee $\mathrm{P} \mathrm{S}$, Bandhyopadhyay A: Validity of Queen's College step test for use with young Indian men. Br J Sports Med 2004; 38: 289-291.

Chatterjee S, Chatterjee P, Bandhyopadhyay A: Validity of Queen's College Step test for estimation of maximum oxygen uptake in female students. Indian J Med Res 2005; 121: 32-35.

Prajapati R, Upadhyay-Dhungel K, Parmanik T, Gosh A, Roychowdhury P: Assessment of some pulmonary parameters and cardiorespiratory fitness status in Nepalese medical Students. Nepal Med Coll J 2008; $10(1): 28-29$. 
9. Sadhan B, Koley S, Sandhu J S: Relationship between Cardiorespiratory fitness, body composition and blood pressure in Punjabi Collegiate Population. J.Hum.Ecol 2007; 23(3):215-219.

10. Liu C M, Lin K F: Estimation of $\mathrm{VO}_{2}$ max: $\mathrm{A}$ comparative analysis of post exercise heart rate and physical fitness index from 3 minute step test. $J$ ExercSci Fit 2007; 5(2):118-123.

11. Chatterjee S, Dey SK, Nag SK: Maximum Oxygen uptake capacity of smoker of different age group. Jpn J Physiol 1987; 37(5):837-50.

12. Huie M J: Effect of smoking on exercise performance. Sports Med 1996; 22(6):355-359.

13. Gormley S E, Swain D P, High R et al: Effect of intensity of aerobic training on $\mathrm{VO}_{2}$ max. Medicine and science in sports and exercise 2008:1336-1343. 